NEUTRON SCATTERING STUDIES OF INDUSTRY-RELEVANT MATERIALS:

CONNECTING MICROSCOPIC BEHAVIOR TO APPLIED PROPERTIES*

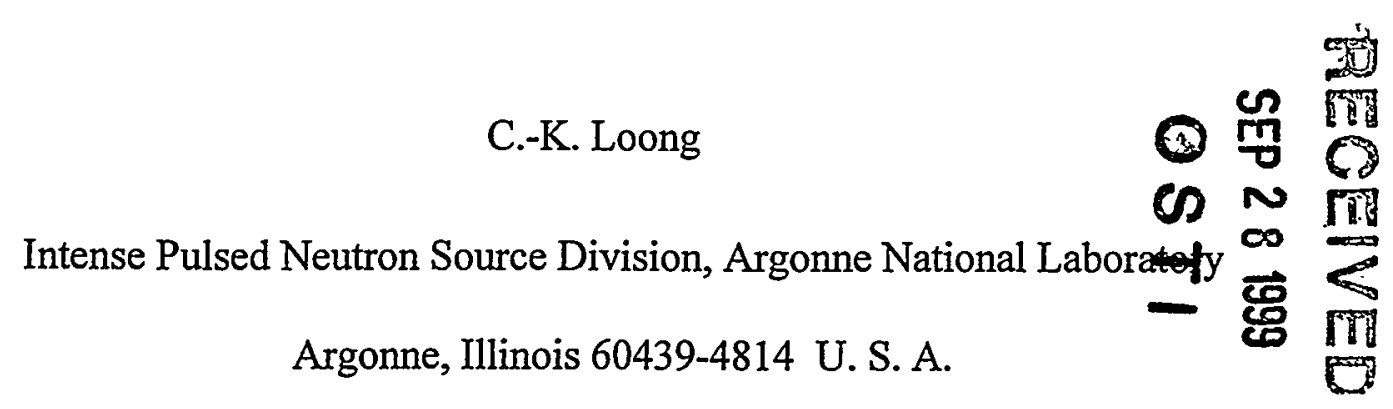

The submitted manuscript has been created by the University of Chicago as Operator of Argonne National Laboratory ("Argonne") under Contractor No. W-31-109-ENG-38 with the U.S. Department of Energy. The U.S. Government retains for itself, and others acting on its behalf, a paid-up, nonexclusive, irrevocable worldwide license in said article to reproduce, prepare derivative works, distribute copies to the public, and perform publicly and display publicly, by or on behalf of Government.

An invited paper presented in The $7^{\text {th }}$ ISSP International Symposium on "Frontiers in Neutron Scattering Research", November 24-27, 1998, Roppongi, Tokyo, Japan.

Submitted to the Journal of Physics and Chemistry of Solids

*Work supported by U. S. Department of Energy, BES, contract No. W-31-109-ENG-38

Corresponding author:

Chun Loong

IPNS, Bldg. 360

Argonne National laboratory

9700 S. Cass Ave

Argonne, IL 60439-4814

U. S. A.

Tel: 630-252-5596

FAX: 630-252-4163

Email: ckloong@ anl.gov 


\section{DISCLAIMER}

This report was prepared as an account of work sponsored by an agency of the United States Government. Neither the United States Government nor any agency thereof, nor any of their employees, make any warranty, express or implied, or assumes any legal liability or responsibility for the accuracy, completeness, or usefuiness of any information, apparatus, product, or process disclosed, or represents that its use would not infringe privately owned rights. Reference herein to any specific commercial product, process, or service by trade name, trademark, manufacturer, or otherwise does not necessarily constitute or imply its endorsement, recommendation, or favoring by the United States Government or any agency thereof. The views and opinions of authors expressed herein do not necessarily state or reflect those of the United States Government or any agency thereof. 


\section{DISCLAIMER}

Portions of this document may be illegible in electronic image products. Images are produced from the best available original document. 


\title{
NEUTRON SCATTERING STUDIES OF INDUSTRY-RELEVANT MATERIALS: CONNECTING MICROSCOPIC BEHAVIOR TO APPLIED PROPERTIES
}

\author{
C.-K. Loong \\ Intense Pulsed Neutron Source Division, Argonne National Laboratory, \\ Argonne, Illinois 60439-4814 U. S. A.
}

\begin{abstract}
Certain systems of oxides, nitrides and carbides have been recognized as the basic components of advanced materials for applications as engineering and electronic ceramics, catalysts, sensors, etc. under extreme environments. An understanding of the basic atomic and electronic properties of these systems will benefit enormously the industrial development. of new materials featuring tailored properties. We present an overview of neutron-scattering studies of the crystal phases, microstructure, phonon and magnetic excitations of key materials including rare-earth phosphates, phosphate glasses, nanostructured metal oxides, as well as silicon nitride and silicon carbide ceramics. A close collaboration among neutronscattering experimentation, molecular-dynamics simulation and material synthesis is emphasized.
\end{abstract}

Keywords:

A. ceramics, A. nanostructures, B. neutron scattering, D. microstructure, D. phonons 


\section{Introduction}

The application of neutron scattering for research in condensed-matter physics and chemistry has a long and successful history in studying fundamental properties of model systems. Such endeavors have significantly contributed to our present-day understanding of matter - from phase transformations to magnetism to polymers and other areas. While this will be a continuing mission for modern neutron facilities, an emerging area of importance is related to the characterization of practical, industry-relevant materials. Industries respond keenly to two factors: the costs of materials and processing, and regulatory forces imposed by governments. The method of neutron scattering can provide valuable knowledge toward the development of cost-effective means for materials preparation and processing. Neutron facilities are funded by governments, thus these organizations are obliged to provide technical support to industries for the fulfillment of governmental policies. For decades neutron technologists and instrument scientists have striven to improve the neutron sources and instrumentation for condensed-matter research. Future high-tech applications will undoubtedly demand materials for carrying out complex tasks under stringent or adverse conditions. Therefore, we anticipate increasing collaborations between neutron scientists and industrial researchers in years to come. In this paper, a description of potential applications of neutron scattering for industrial problems is presented, using recent studies of phosphates, oxide catalysts, nitrides and carbides as examples.

\section{Phosphates as luminescent, optical, and composite materials}

\subsection{Rare-earth orthophosphates}

Rare-earth orthophosphates, $\mathrm{RPO}_{4}(\mathrm{R}=$ rare-earth elements), are known for their outstanding properties. Their high melting temperatures (about $2000^{\circ} \mathrm{C}$ ), structural and 
chemical stability, and long-term corrosion resistance make these substances attractive for such applications as high-temperature components and nuclear waste storage media.[1] The optical properties of the rare-earth ions in $\mathrm{RPO}_{4}$ hosts, particularly rare-earth-activated luminescence, have found application in scintillators and phosphors. For example, in 1995, General Electric's Lighting Division introduced a new, long-life $(10,000 \mathrm{~h})$ household light bulb, known as the E-lamp.[2] It employs $\mathrm{LaPO}_{4}: \mathrm{Ce}^{3+}, \mathrm{Tb}^{3+}$ as green phosphors. The lamp produces 75-watt-equivalent light while consuming 23 watts of electrical power. Moreover, cerium-doped $\mathrm{LuPO}_{4}$ is found to be one of the most effective scintillator materials.[3] The magnetic phase transitions and Jahn-Teller effects associated with some $\mathrm{RPO}_{4}$ compounds also have prompted many fundamental investigations, as well as suggesting magnetic refrigerant applications. [4] More recently, two-phase composites consisting of rare-earth orthophosphates $\left(\mathrm{RPO}_{4}, \mathrm{R}=\right.$ rare earths $)$ and alumina were found to be machinable, and alumina fibers coated with rare-earth phosphates were superior to bare fibers in the prevention of fiber puncture.[5] These phenomena are thought to be related to the relatively weak interfaces between alumina and phosphates. In collaboration with L. A. Boatner, L. Soderholm and other colleagues, we have initiated a systematic neutron-scattering study of the thermodynamic and magnetic properties of the $\mathrm{RPO}_{4}$ system. It is hoped that the knowledge gained from these investigations will lead to the eventual development of new phosphate materials with properties tailored for advanced technological applications.

Fig. 1 exemplifies the three areas of interest in the neutron conducted studies thus far. First, the phonon dispersion relations along major symmetry directions and the phonon density of states (DOS) of $\mathrm{LuPO}_{4}$, the non-magnetic end member of the xenotime series, were determined by single-crystal and powder measurements.[6] The neutron results 
provided an microscopic understanding of many basic thermodynamic properties, such as the $"$ normal modes of atomic vibrations, lattice specific heat, and elastic constants, which are important to energy-transfer processes in the host lattice of lasers, dielectric response of optical crystals, and mechanical properties of refractories employing $\mathrm{RPO}_{4}$ materials. Second, the rare-earth ionic wavefunctions in $\mathrm{RPO}_{4}$ were determined by crystal-field spectroscopy which in turn provided a means to calculate magnetic properties, such as the paramagnetic susceptibility and specific heat, saturated magnetization, and effective exchange fields, which are essential for luminescent applications.[7-10] Third, the magnetostriction in several $\mathrm{RPO}_{4}$ compounds was investigated.[11-13] These properties are important to the development of sensors and functional composites. Further neutron studies of strain distribution and microstructure in . $\mathrm{RPO}_{4} /$ oxides interfaces by small-to-wide angle scattering and reflectivity measurements are underway.

\subsection{Phosphate glasses}

It is well known that the chemical durability, optical properties, and thermomechanical behavior of a glassy system may undergo drastic changes as its composition varies. These complex phenomena imply numerous opportunities for development of novel materials and devices for technological applications, provided an understanding of the systematics and physical origins of such behavior is established to guide the development efforts. So far, industrial investments in phosphate glasses as compared to their silicate analogues have been limited due to concerns of cost and chemical instability of the parent materials. Only recently has the technological importance of phosphate glasses and glass-ceramics been recognized. In collaboration with K. Suzuya, B. C. Sales, L. A. 
Boatner and D. L. Price, we began neutron diffraction and spectroscopic studies of a number of phosphate glasses that show promising industrial applications.[14-18]

Lead-indium phosphate and lead-scandium phosphate glasses exhibit a number of useful properties.[19] These glasses have an index of refraction of $1.75-1.83$ in the visible region, an ultraviolet absorption edge at a wavelength near $300 \mathrm{~nm}$, and strong infrared absorption beyond $2800 \mathrm{~nm}$. The preparation temperatures are relatively low (900 to $1000^{\circ}$ C), and the chemical durability and resistance to both weathering and $\gamma$-radiation are good.

Fig. 2 shows the neutron intensity spectra of a $(\mathrm{PbO})_{56.3}\left(\mathrm{In}_{3} \mathrm{O}_{2}\right)_{4.2}\left(\mathrm{P}_{2} \mathrm{O}_{5}\right)_{39.5}$ glass observed at two typical scattering angles. At $2 \theta=27.5^{\circ}$, strong absorption due to resonances of the ${ }^{115}$ In nuclei at 1.46 and $3.86 \mathrm{eV}$ were seen at 12.5 and $20 \AA^{-1}$, respectively, whereas at $2 \theta=$ $92.5^{\circ}$, the intensity profile is not affected because the resonances occur at $\mathrm{Q}$ values beyond $35 \AA^{-1}$. This illustrates the potential for investigating the structural and dynamic response of certain dopant nuclei in a disordered system by means of anomalous neutron scattering, an area that has not been well utilized thus far. Even using the traditional method of analysis, the In-O distance (2.1 $\AA$ ), and coordination number (5.5) can be determined and be compared with those of $\mathrm{Pb}-\mathrm{O}(2.52 \AA, 5.2)$ in the glass. The neutron data suggest that an octahedral surrounding $\left(\mathrm{N}_{\mathrm{M}-\mathrm{O}}=6\right)$ is appropriate for the modeling of the electronic environment for the In (and Sc) ions, and the cation-induced structural organization of the building blocks of the $\mathrm{PO}_{4}$ tetrahedra and the $\mathrm{MO}_{\mathrm{n}}$ polyhedra is crucial to enhancement of chemical durability for lead-phosphate glasses.[18]

\section{Rare-earth and transition-metal modified zirconia and alumina as catalytic} materials 
High-surface-area zirconia and alumina powders are widely used as promoters and/or support components in automobile-exhaust emission-control catalysts to remove poisonous gases, such as $\mathrm{CO}, \mathrm{NO}_{\mathrm{x}}$, and hydrocarbons. Doping rare-earth elements into zirconia to form solid solutions of $\mathrm{R}-\mathrm{Zr}$ oxides is an effective approach to improve the thermal stability of the catalysts. These mixed oxides are partially stabilized to the cubic and tetragonal phases and are free from any disruptive structural transformation over a wide temperature range. Furthermore, owing to the low redox potential of nonstoichiometric $\mathrm{CeO}_{2}$, oxygen release and intake associated with the conversion between the $\mathrm{Ce}^{3+}$ and $\mathrm{Ce}^{4+}$ oxidation states provide the oxygen storage capacity that is essentially to effective catalytic functions under the "leanburning" condition of the engine.[20] In the search for de-NOx catalysts suitable to leanburn engines, $\mathrm{Cu}-\mathrm{Al}_{2} \mathrm{O}_{3}$ and $\mathrm{Cu}$ ion exchanged $\mathrm{ZSM}-5$ zeolite have been reported to be effective in the presence of some reductants despite an excess of oxygen and large space velocity.[21, 22] $\mathrm{Cu}-\mathrm{Al}_{2} \mathrm{O}_{3}$ has the advantage of having a more robust structure under hydrothermal conditions at high temperatures than the zeolite counterpart. In collaboration with M. Ozawa and S. Suzuki, we have undertaken a series of neutron-scattering measurements to characterize the microscopic properties of high-surface-area R-zirconia and Cu-alumina materials.

First, the growth of primary particles from hydrolysis or coprecipitation in $\mathrm{ZrOCl}_{2}$ aqueous solutions, and the microstructural evolution due to annealing the obtained pure and $\mathrm{R}$-modified $\mathrm{ZrO}_{2}$ powders were studied by small-angle scattering.[23, 24] Second, through powder diffraction the different crystal phases and the oxygen-vacancy induced defects in $\mathrm{RE}-\mathrm{ZrO}_{2-\mathrm{x}}(\mathrm{RE}=\mathrm{La}, \mathrm{Ce}$ and $\mathrm{Nd})$ were characterized.[25] The $\gamma \rightarrow \delta \rightarrow \theta \rightarrow \alpha$ transformations over a temperature range of $450^{\circ}-1300^{\circ} \mathrm{C}$ in pure and La-doped alumina were monitored by 
in situ experiments and the effect of $\mathrm{La}$ doping on the up-shifting of the $\alpha-\mathrm{Al}_{2} \mathrm{O}_{3}$ formation temperature was determined.[26, 27] Third, the dynamics of hydrogen atoms associated with the surface hydroxyl groups and adsorbed water molecules on $\mathrm{Nd}_{0.1} \mathrm{Zr}_{0.9} \mathrm{O}_{1.95}$ and pure $\mathrm{ZrO}_{2}$ over a frequency range of $0-4400 \mathrm{~cm}^{-1}$ was investigated by inelastic scattering.[28] Finally, the redox behavior up to $\sim 1000 \mathrm{~K}$ of Pt-impregnated $\mathrm{CeO}_{2}-\mathrm{ZrO}_{2}$ solid solutions was investigated.[29, 30] The samples were heated first in flowing $2 \% \mathrm{O}_{2} / \mathrm{Ar}$ from room temperature to $400^{\circ} \mathrm{C}$ and then in $1 \% \mathrm{CO} / \mathrm{Ar}$ to about $700^{\circ} \mathrm{C}$. A discontinued increase of the tetragonal unit-cell volume, a decrease of tetragonality, and a change of color from light yellow to gray when changing from oxidizing to reducing atmosphere were observed only in the sample containing Pt. This result supports the model of metal-support interaction that assumes the formation of oxygen vacancies initially near the $\mathrm{Pt}$ atoms. As more Ce ions are reduced from $4+$ to $3+$ oxidation states at high temperatures, oxygen vacancies migrate to the bulk of the oxide particles.

\section{Silicon-nitride and silicon-carbide based ceramics as high-temperature, high- strength materials}

At room temperature the tensile strength of typical steels varies from 1 to $1.4 \mathrm{GPa}$, which is two to three times of the flexure strength of the toughest sintered ceramics like silicon nitride or silicon carbide. Therefore, there is little incentive to develop strong ceramic materials for applications under ambient conditions. However, at $1100^{\circ} \mathrm{C}$ metals soften and become useless, yet the strength of ceramics is essentially unchanged. Moreover, at high temperatures ceramics in general have higher hardness, lower density, lower thermal expansion, and better corrosion and oxidation resistance than metals. Hence advanced 
ceramics are the major contenders for high-temperature applications. Currently, the strength and reliability of nitride and carbide ceramics are not sufficient to meet the demands of hightech applications such as heat engines. A large $\mathrm{R} \& \mathrm{D}$ effort is needed to advance the field of ceramic science and engineering.

Fig. 3 shows the phase diagram of the $\mathrm{SiO}_{2}-\mathrm{Si}_{3} \mathrm{~N}_{4}-\mathrm{AlN}-\mathrm{Al}_{2} \mathrm{O}_{3}$ system which encompasses many of the most promising ceramics for high-temperature applications.[31] A rigorous and systematic study of the end compounds, silica, silicon nitride, aluminum nitride and alumina, will pave the way for further development of new ceramic alloys and composites possessing superior properties. An understanding of the atomic dynamics in these monolithic compounds is an important prerequisite. In collaboration with R. Kalia, P. Vashishta, S. Suzuki, M. Ozawa, M. Winterer and other colleagues, we began joint neutronscattering and molecular-dynamics (MD) simulation studies of the thermodynamic and mechanical properties of some key nitride and carbide ceramics. First, the phonon densities of states of $\mathrm{SiO}_{2}, \mathrm{Si}_{3} \mathrm{~N}_{4}, \mathrm{AlN}$, and $\alpha-\mathrm{Al}_{2} \mathrm{O}_{3}$ were measured by neutron spectroscopy and the results were analyzed quantitatively by either $\mathrm{MD}$ simulations or lattice-dynamics model calculations.[32, 33] Second, the thermodynamic properties such as lattice specific heat, Debye temperatures, elastic constants were calculated and compared with experimental values.[34, 35] Finally, the accumulative experience from neutron and MD investigations of the parent ceramics is utilized for further studies of the ceramic alloys, such as $\beta$-sialons, AlONs, and AIN/GaN-based alloys.[36, 37]

A major drawback of ceramics is their brittleness, which results in low fracture toughness and thus prevents their use as structural materials. In polycrystalline materials the 
mechanical strength depends, to a large extent, on the intergranular microstructure. One approach for improving the fracture toughness of ceramics is to fabricate composite materials with tailored microstructures. Neutron-scattering techniques can be applied to determine the residual-strain distribution in these materials. Another approach is to synthesize bulk ceramics by consolidation of nanometer size particles. It has been observed that such ceramics become much more ductile presumably due to the presence of a large number of atoms in inter-particle regions thereby allowing large plastic deformations. Recently, the structure, mechanical properties and sintering of nanostructured $\mathrm{SiC}$ were investigated by neutron scattering and large-scale MD simulations.[38] Both $\mathrm{MD}$ and experiments indicate the onset of sintering around $1500 \mathrm{~K}$, which is much lower than the sintering temperature for coarse-grained $\mathrm{SiC}$. In sintered $\mathrm{n}-\mathrm{SiC}$ system at different densities, $\mathrm{MD}$ simulations show similar pore morphology with a fractal dimension $\sim 2.4$ and surface roughness exponent 0.45. The value of the fractal dimension of pores is in good agreement with small-angle neutron scattering measurements. The MD simulations reveal that the primary sintering mechanism is surface diffusion of atoms, and the inter-particle regions are highly disordered. Once the parameters for the interatomic potential were validated by the neutron data, $\mathrm{MD}$ simulations can assess various mechanical properties at high temperatures and under high pressures.

\section{Conclusion}

We have described several studies of phosphates, oxides, nitride and carbide ceramics, attempting to demonstrate the usefulness of neutron-scattering techniques to vital industrial interests in materials characterization. Limitation in space forbids an in-depth discussion of individual scientific cases. However, the need for cooperative collaboration between basic 
and industrial research is clear. This includes continuing improvement of neutron sources and instrumentation for characterization of industrial materials under extreme environments, effective communication between materials scientists, neutron technologists, and industrial researchers for information exchange and mutual support, and finally, an infrastructure to ensure the protection of intellectual rights and interests between all parties.

\section{Acknowledgment}

I am indebted to many collaborators: M. M. Abraham, L. A. Boatner, T. J. Campbell, A. Chatterjee, I. Ebbsjö, R. K. Kalia, A. Nakano, J. C. Nipko, M. Ozawa, D. L. Price, J. W. Richardson, Jr., B. C. Sales, S. Skanthakurma, L. Soderholm, S. Suzuki, K. Suzuya, P. Thiyagarajan, and P. Vashishta with whom I have enjoyed working in the course of these studies. Work performed at Argonne National Laboratory is supported by the U. S. DOEBES under Contract No. W31-109-ENG-38. 


\section{References}

1. Boatner, L. A. and Sales, B. C., in "Radioactive waste forms for the future.", (W. Lutze and R. C. Ewing, p. 495. Elsevier Science, 1988.

2. Rare-Earth Information-Center News 30 (1995).

3. Wojtowicz, A. J., Lempicki, A., Wisniewski, D., and Boatner, L. A., Mat. Res. Soc. Symp. Proc. 348, 123 (1994).

4. Delpuech, C., Beranger, R., Mardion, G. B., Claudet, G., and Lacaze, A. A., Cryogenics , 579 (1981).

5. Marshall, D. B., Morgan, P. E. D., Housley, R. M., and Cheung, J. T., J. Am. Ceram. Soc. 81, 951 (1998).

6. Nipko, J. C., Loong, C.-K., Loewenhaupt, M., Braden, M., Reichardt, W., and Boatner, L. A., Phys. Rev. B 56, 11584 (1997).

7. Loong, C.-K., Soderholm, L., Goodman, G. L., Abraham, M. M., and Boatner, L. A., Phys. Rev. B 48, 6124 (1993).

8. Loong, C.-K., Soderholm, L., Hammonds, J. P., Abraham, M. M., Boatner, L. A., and Edelstein, N. M., J. Phys.: Condens. Matter 5, 5121 (1993).

9. Loong, C.-K., Soderholm, L., Abraham, M. M., Boatner, L. A., and Edelstein, N. M., J. Chem. Phys. 98, 4214 (1993).

10. Loong, C.-K., Soderholm, L., Xue, J. S., Abraham, M. M., and Boatner, L. A., J. Alloys Compounds 207-208, 165 (1994). 
11. Nipko, J., Grimsditch, M., Loong, C.-K., Kern, S., Abraham, M. M., and Boatner, L. A., Phys. Rev. B 53, 2286 (1996).

12. Skanthakumar, S., Loong, C.-K., Soderholm, L., Richardson, J. W., Jr., Abraham, M. M., and Boatner, L. A., Phys. Rev. B 51, 5644 (1995).

13. Skanthakumar, S., Loong, C.-K., Soderholm, L., Nipko, J., Richardson, J. W., Jr., Abraham, M. M., and Boatner, L. A., J. Alloys Compounds 225, 595 (1995).

14. Loong, C.-K., Suzuya, K., Price, D. L., Sales, B. C., and Boatner, L. A., Physica B 241-243, 890 (1998).

15. Suzuya, K., Price, D. L., Loong, C.-K., Sales, B. C., and Boatner, L. A., Mat. Res. Soc. Symp. Proc. 376, 661 (1995).

16. Suzuya, K., Price, D. L., Loong, C.-K., and Martin, S. W., J. Non-Cryst. Solids 232234, 650 (1998).

17. Suzuya, K., Price, D. L., Loong, C.-K., and Martin, S. W., J. Chem. Phys. , submitted (1998).

18. Suzuya, K., Loong, C.-K., Price, D. L., Sales, B. C., and Boatner, L. A., J. Non-Cryst. Solids, submitted (1998).

19. Sales, B. S. and Boatner, L. A., J. Am. Ceram. Soc. 70, 615 (1987).

20. Ozawa, M., Kimura, M., Matsumoto, S., and Miyoshi, N., U. S. Patent No. 5,075,276 (1991).

21. Ozawa, M., Toda, H., Kato, O., and Suzuki, S., Appl. Catalysis B 8, 123 (1996).

22. Ozawa, M., Toda, H., and Suzuki, S., Appl. Catalysis B 8, 141 (1996). 
23. Ozawa, M., Suzuki, S., Loong, C.-K., and Thiyagarajan, P., J. Mat. Sci. Lett. 16, 1360 (1997). .

24. Loong, C.-K., Thiyagarajan, P., Richardson, J., J. W., Ozawa, M., and Suzuki, S., J. Catal. 171, 498 (1997).

25. Loong, C.-K., Richardson, J. W., Jr., and Ozawa, M., J. Catal. 157, 636 (1995).

26. Loong, C.-K., Richardson, J. W., Jr., and Ozawa, M., J. Alloys Compounds 250, 356 (1997).

27. Ozawa, M. and Loong, C.-K., Physica B 241-243, 269 (1998).

28. Loong, C.-K., Iton, L. E., and Ozawa, M., Physica B 213 \& 214; 640 (1995).

29. Loong, C.-K., Short, S. M., Ozawa, M., and Suzuki, S., Mat. Res. Soc. Symp. Proc. 497, in press (1998).

30. Ozawa, M. and Loong, C.-K., Catal. Today , in press (1998).

31. Jack, K. H., J. Mat. Sci. 11, 1135 (1976).

32. Loong, C.-K., Vashishta, P., Kalia, R. K., and Ebbsjö, I., Europhys. Lett. 31, 201 (1995).

33. Loong, C.-K., Mat. Res. Soc. Symp. Proc. 395, 423 (1996).

34. Nipko, J. C. and Loong, C.-K., Phys. Rev. B 57, 10550 (1998).

35. Loong, C.-K., Journal of European Ceramic Society , submitted (1998).

36. Loong, C.-K., Richardson, J. W., Jr., Suzuki, S., and Ozawa, M., J. Am. Ceram. Soc. 79,3250 (1996). 
37. Nipko, J. C., Loong, C.-K., Balkas, C. M., and Davis, R. F., Appl. Phys. Lett. 73, 34 (1998).

38. Chatterjee, A., Kalia, R. K., Nakano, A., Omeltchenko, A., Tsuruta, K., Vashishta, P., Loong, C.-K., Winterer, M., and Klein, S., Phys. Rev. Lett. , submitted (1998). 


\section{Figure Captions}

Figure 1. Examples of neutron-scattering studies of rare-earth orthophosphates: (a) the phonon dispersion relations in $\mathrm{LuPO}_{4}$, (b) the ground-state wavefunctions of $\mathrm{Yb}^{3+}$ ions in $\mathrm{YbPO}_{4}$, and (c) the anomalous thermal expansion along the crystallographic a-direction in $\mathrm{HoPO}_{4}$ due to quadrupolar interactions between the magnetic ions and the host lattice.

Figure 2. The neutron-intensity spectra of the Pb-In-P-O glass observed at scattering angles

_... of $27.5^{\circ}$ and $92.5^{\circ}$. In the $27.5^{\circ}$ spectrum, resonances of the ${ }^{115}$ In nuclei result in a depletion of the intensity at 12.5 and $20 \AA^{-1}$. These resonances are not seen in the $92.5^{\circ}$ spectrum because they occur at much higher $\mathrm{Q}\left(>35 \AA^{-1}\right)$.

Figure 3. The phase diagram of the $\mathrm{SiO}_{2}-\mathrm{Si}_{3} \mathrm{~N}_{4}-\mathrm{AlN}-\mathrm{Al}_{2} \mathrm{O}_{3}$ system, after Ref. 31 . 


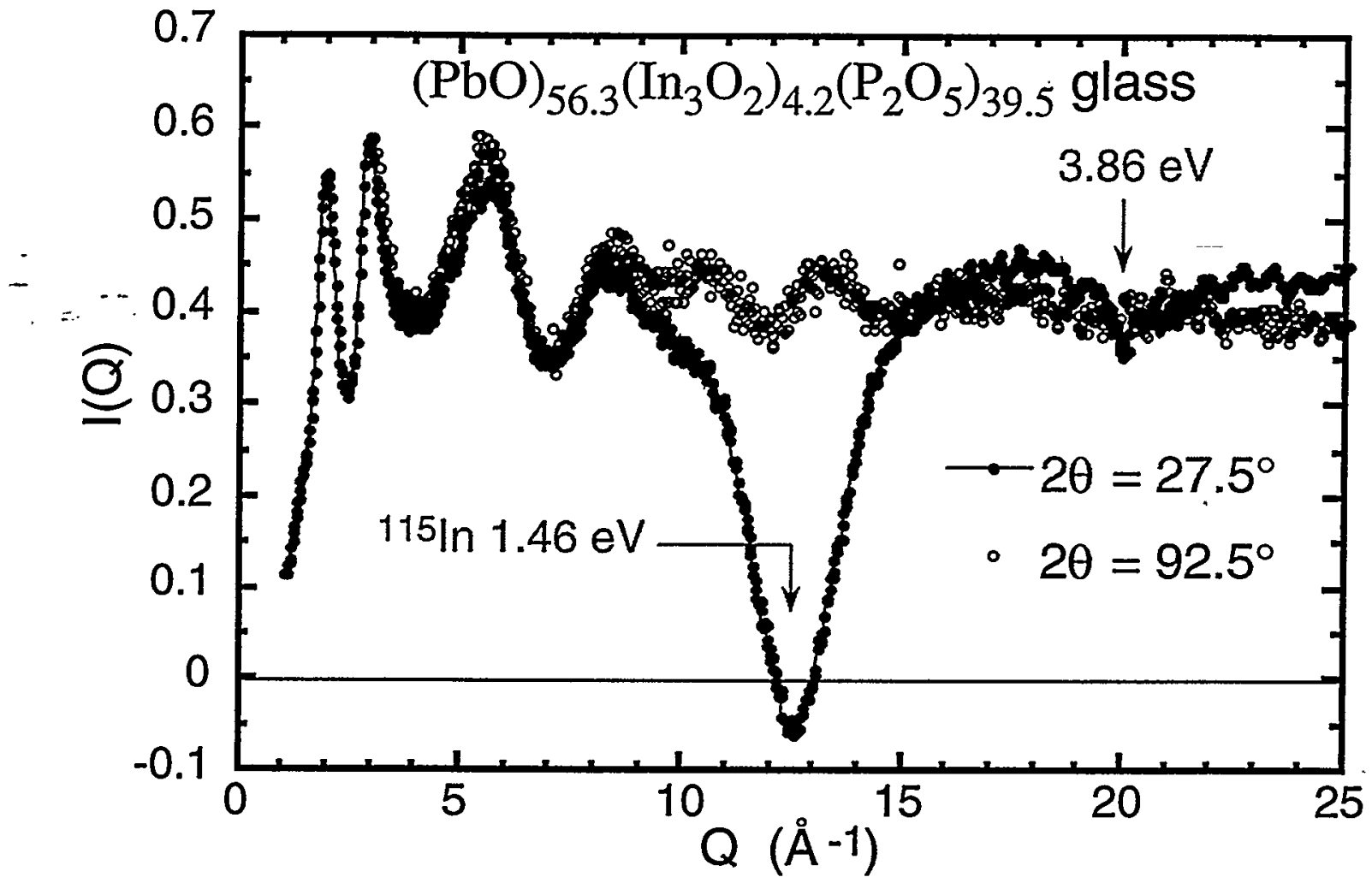

Fig. 3, Loong, "Neutron scattering studies of industry-relevant materials..." 
(a)
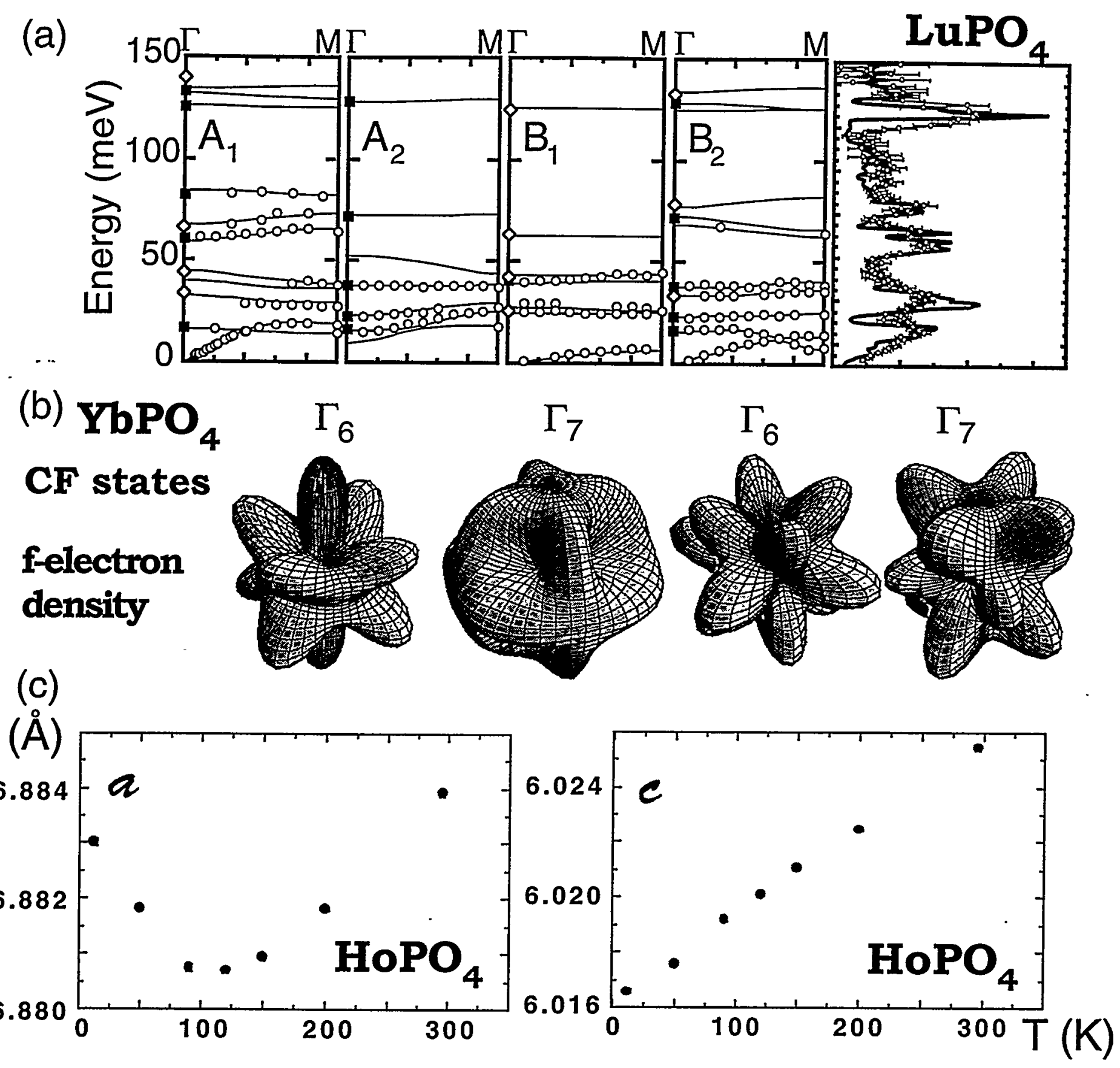

Fig. 1, Loong, "Neutron scattering studies of industry-relevant materials..." 


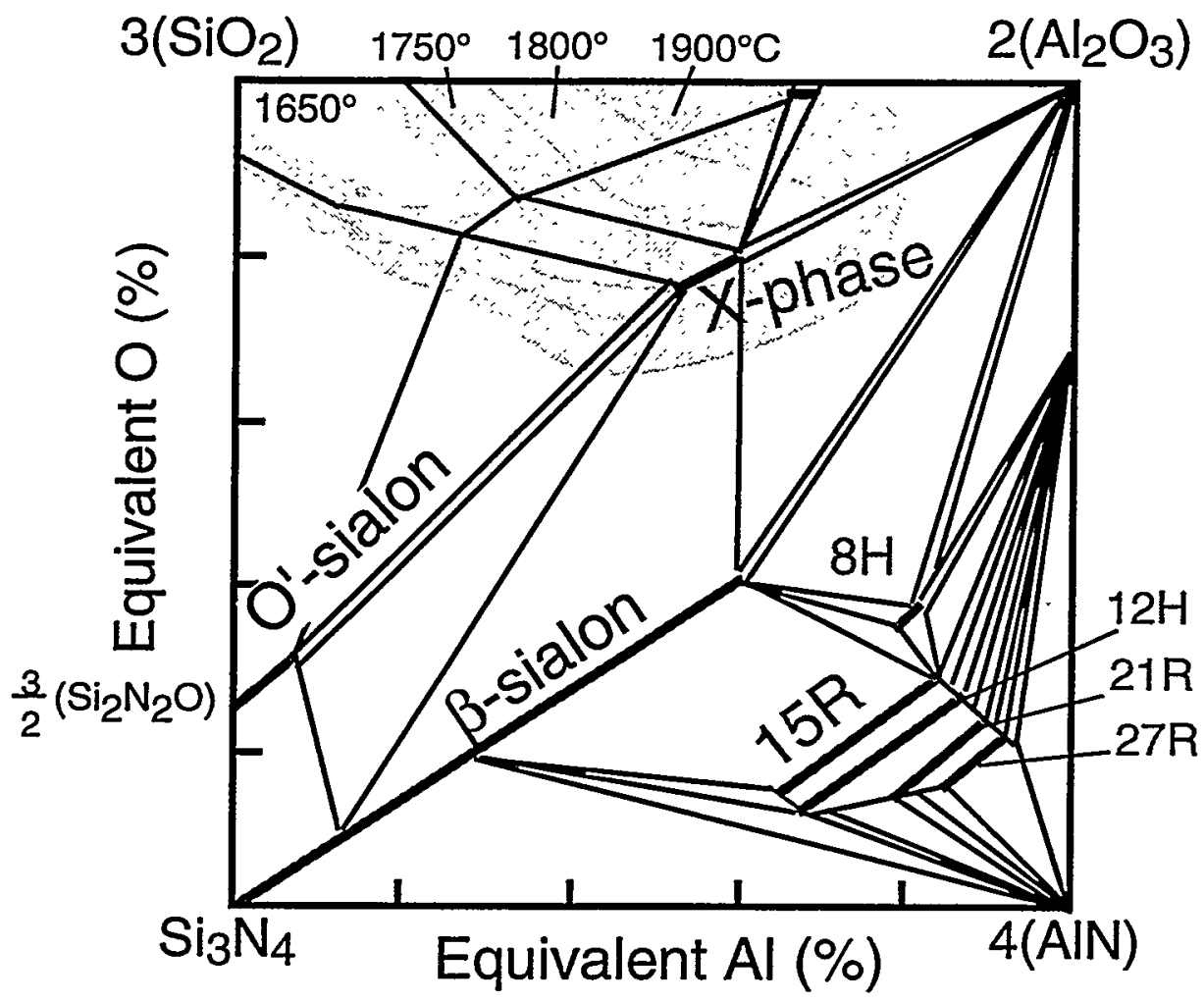

Fig. 2, Loong, "Neutron scattering studies of industry-relevant materials..." 


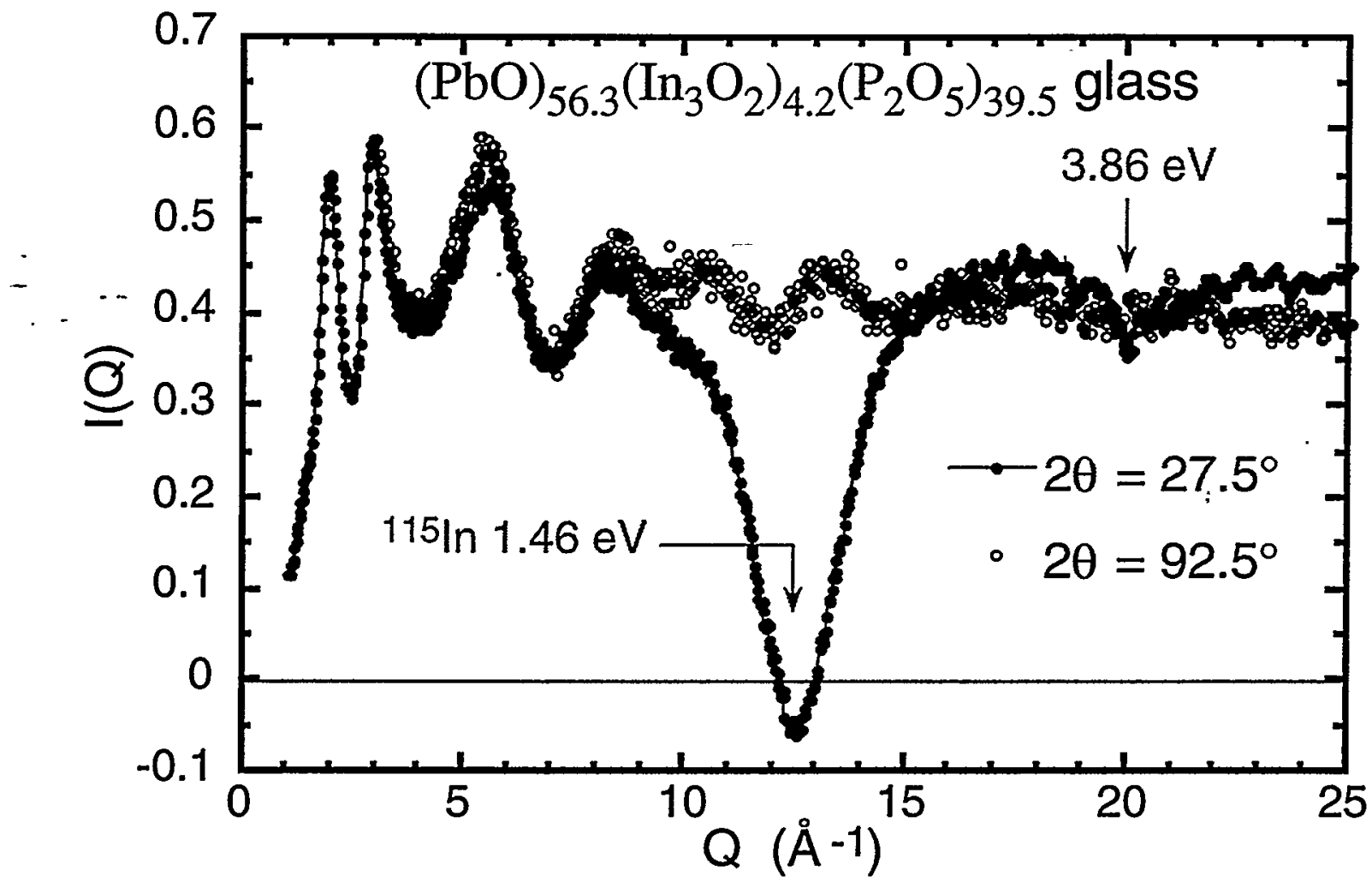

Fig. 3, Loong, "Neutron scattering studies of industry-relevant materials..." 